\title{
Trazos de agrimensura: soberanía, límites y rebelión en José Eustasio Rivera
}

Este artículo explora las conexiones entre agrimensura y literatura en la obra de José Eustasio Rivera. Partiendo de la colaboración de Rivera en la Comisión de Límites colombo-venezolana (1922) y la proyección de esta experiencia en La vorágine, se argumenta que la novela expone la complicidad entre el Estado liberal latinoamericano y las compañías multinacionales del caucho. También se examinan las esporádicas referencias a rebeliones de indígenas y peones caucheros en La vorágine como inscripciones literarias que señalan el agotamiento de la relación entre límites y ley en el contexto de la bonanza del caucho en la Amazonía.

Palabras claves: José Eustasio Rivera, La vorágine, agrimensura, soberanía, extractivismo

This article explores the connections between land surveying and literature in the work of José Eustasio Rivera. Based on Rivera's collaboration in the Colombia-Venezuela Border Commission (1922) and the projection of this experience in La vorágine, the article argues that the novel exposes the complicity between the Latin American liberal State and the multinational rubber companies. It also examines the sporadic references to indigenous and rubber tapper rebellions in La vorágine as literary inscriptions that point to the exhaustion of the relationship between boundaries and law in the context of the Amazon Rubber Boom.

Keywords: José Eustasio Rivera, The Vortex, surveying, sovereignty, extractivism

Aunque pocas veces abordadas de manera explícita, las relaciones entre agrimensura y literatura, es decir, las interacciones ficcionales o de otro tipo entre el oficio de escribir y la práctica de trazar y fijar límites o fronteras, han ocupado un lugar destacado en la producción literaria e intelectual de una amplia gama de autores. Quizás una de las instancias mejor conocidas sea El Castillo (1926), la novela de Franz Kafka en cuya trama figura un misterioso agrimensor que jamás logra acceder a las autoridades de la villa a la que ha llegado por error. Otro caso 
sobresaliente, aunque por razones distintas, lo encontramos en el escritor trascendentalista y ambientalista norteamericano Henry David Thoreau. La composición de Walden (1854), su libro más conocido, estuvo condicionada en más de un sentido por su labor como agrimensor profesional de terrenos en Massachusetts. ${ }^{\mathrm{I}}$ En el contexto latinoamericano, las relaciones entre agrimensura y literatura cobran especial notoriedad a finales del siglo diecinueve y durante la primera mitad del siglo veinte, particularmente (si bien no exclusivamente) en la producción de la llamada literatura regional y, en general, en obras donde predominan las temáticas rurales y la mirada letrada hacia los lindes y márgenes no modernizados del Estado-nación. En Brasil, por ejemplo, Euclides da Cunha compone À margem da história (1909), su colección de ensayos amazónicos, luego de participar en una comisión binacional de límites en la región de Acre; Alberto Rangel, por su parte, trabajó como agrimensor de seringales en las inmediaciones de Manaos al tiempo que escribía los cuentos de Inferno verde (1908), durante la bonanza del caucho en la Amazonía. Rómulo Gallegos aprovechó su formación como ingeniero y agrimensor para viajar y acumular datos sobre los llanos venezolanos que luego plasmaría en algunos pasajes de Doña Bárbara (1929), y algunas de las obras de escritores como Leopoldo Lugones, César Vallejo y Ciro Alegría desarrollan ficcionalizaciones de agentes vinculados al trazado de límites y la parcelación de la tierra. ${ }^{2}$

El caso del abogado y escritor colombiano José Eustasio Rivera no es una excepción a esta tendencia. Pocos años antes de la publicación de $L a$ vorágine (1924), Rivera fue nombrado secretario oficial de una Comisión de Límites colombo-venezolana en la Amazonía noroccidental, experiencia que le permitiría familiarizarse con la siniestra economía de la explotación del caucho y más tarde influenciaría notablemente la composición de su conocida novela. Si bien Rivera no tenía la formación técnica de un agrimensor, su propia trayectoria como abogado lo introdujo pronto en el terreno de las disputas territoriales y la demarcación de fronteras. En efecto, tras el éxito de la tesis que presentó a la Universidad Nacional de Colombia para recibirse como Doctor en Derecho (Liquidación de las herencias), el escritor fue contratado por un hacendado para dirimir un complicado litigio de tierras en Casanare, una región fronteriza con Venezuela. ${ }^{3}$ Posteriormente se involucra con el Ministerio de Relaciones Exteriores, trabajo que lo lleva a participar en diferentes delegaciones diplomáticas con las que viaja por México, Cuba y Perú, y que además lo pone en contacto con la historia de los tratados internacionales y las disputas limítrofes de Colombia con sus países vecinos. Por otra parte, cuando en 1922 Rivera inicia sus trabajos con la Comisión de Límites, no 
solo permanecía viva la memoria de la separación de Panamá (1903) en el discurso nacional, sino que seguían vigentes antiguos desacuerdos territoriales con Perú y Venezuela en la Amazonía agudizados por la expansión descontrolada de la economía cauchera, lo cual teñía de urgencia el tema de la protección de las fronteras nacionales que ocuparía al escritor durante buena parte de su labor como funcionario público.

Mi interés por los vínculos de Rivera con la agrimensura, con la problemática general de la definición y el trazado de límites, apunta en principio al examen de la figura del agrimensor en tanto agente generador de ley y soberanía en el contexto amazónico trasnacional de inicios del siglo veinte. Durante estos años, como recuerda Susanna B. Hecht, las fronteras nacionales en la Amazonía no estaban del todo establecidas y el territorio era objeto de enconadas discordias entre los países limítrofes. Aparte del litigio entre Colombia y Venezuela, Perú se disputaba terrenos con Ecuador, Bolivia y Colombia, y Brasil a su vez dirimía sus propios intereses fronterizos con Perú y también con Gran Bretaña en la región guyanesa (I2). No obstante, es importante destacar que mientras la preocupación de Rivera, el agrimensor, estuvo centrada en la demarcación territorial como fundamento del proyecto del Estado modernizador colombiano y latinoamericano, Rivera el escritor, el autor de La vorágine, se posicionará en cambio críticamente frente a ese proyecto, revelando incluso lo que Ericka Beckman describe como "the human consequences" del programa liberal en el continente (159). Como ha sido notado por varios estudiosos, aunque la novela presenta marcados acentos en lo "nacional-estatal", incluso en lo "nacional-popular", La vorágine se despliega al mismo tiempo como una narrativa inestable difícil de interpretar de manera unívoca, ya que constantemente subvierte sus propias premisas y fracasa a la hora de afirmar su propia norma. ${ }^{4}$ En efecto, en su variante más crítica, el texto de Rivera intentó hacer consciente un funesto paradigma de gobernabilidad agenciado por las compañías explotadoras del caucho, el cual produjo nuevas relaciones entre el capitalismo transnacional, la apropiación de tierras, las poblaciones amazónicas y el Estado liberal latinoamericano. Pero es además en aquellas instancias donde la novela no logra mantener su norma, donde inscribe aquello para lo que carece de un lenguaje dentro de su universo axiológico, que La vorágine se convierte en un acto de borradura potencial de los trazos (y por lo tanto del proyecto) del agrimensor. De ello son indicio, como se verá más adelante, las esporádicas referencias a las rebeliones de indígenas y peones caucheros que ocurren en la novela. 
ESPACIALIDAD DE LA LEY: RIVERA Y LA COMISIÓN DE LÍMITES

La función de establecer límites y fijar fronteras ha estado históricamente relacionada con el ejercicio de la ley. En ese sentido, la labor del agrimensor representa una condición de posibilidad para la constitución de la soberanía, entendida en este caso como figura anclada originariamente en la articulación entre ley y territorio. En Desnudez, el filósofo italiano Giorgio Agamben recuerda que en Roma el agrimensor tenía una importancia especial que se cifraba en su doble estatus como "finitor por excelencia", o aquel que "establece, conoce y decide las fronteras", y como "iuris auctor", es decir, "creador de derecho" (Desnudez 42). De ahí que actos como la borradura de fronteras, o como el ejercicio ilegítimo de la agrimensura sin la debida titulación, fueran considerados graves afrentas contra el imperio que convertían al perpetrador en homo sacer - aquel sujeto atrapado en la excepción soberana, proscrito, que podía ser asesinado "impunemente por cualquiera" (Homo sacer 42).5 La relación entre soberanía, ley y parcelación territorial es aludida por Carl Schmitt cuando afirma que en su acepción original la palabra griega nomos, con frecuencia traducida como "norma", "regulación" o "ley", era un término espacial relacionado con las nociones de división, delimitación y partición de la tierra. Según Schmitt, nomos designa fundamentalmente "the first land appropriation understood as the first partition and classification of space" (67), y en consecuencia, "the immediate form in which the political and social order of a people becomes spatially visible ... Nomos is the measure by which the land in a particular order is divided and situated" (70). La división y el cercado del espacio constituyen la precondición, no solo del significado y referencialidad de toda ley subsiguiente, sino también del orden político en general. Este de hecho es producido, visibilizado, a partir de los trazos divisorios que orientan y regulan las relaciones espaciales (67). En la medida en que la soberanía preside la ejecución de la ley, su función es un efecto indisociable del campo de aplicabilidad surgido con el establecimiento de límites. En otras palabras, como sostiene Wendy Brown, "there is first the enclosure and then the sovereign ... it is through the walling off of space from the common that sovereignty is born" (45). La importancia del agrimensor, por consiguiente, radica en ser el agente cuyos actos producen, aseguran y sostienen el vínculo original entre ley, territorio y poder soberano sobre el cual descansa la totalidad del orden político. Aunque la agrimensura designa primordialmente un "proyecto pastoral" basado en la construcción de hitos de propiedad, límites y cercados (Burnett II2), en el contexto americano dicho proyecto significó además la continua transformación de espacios muchas veces conceptualizados como "terra ignota" en territorios 
legalmente incorporados a la jurisdicción de poderes coloniales o Estados nacionales (22). Y en la práctica esto implicaba generar un vasto "aparato intelectual" justificatorio que solía incluir estudios geológicos, cartografía, estudios de campo e informes legales, así como tratados sobre historia diplomática y cultural (Hecht 347$){ }^{6}$

Es a la luz de estas consideraciones que podemos aproximarnos a la participación de Rivera en la Comisión de Límites de i922. Como fue anotado, el propósito de la Comisión había sido dirimir antiguas disputas territoriales entre Colombia y Venezuela en la región del Alto Río Negro, en la Amazonía noroccidental. Este era un asunto que había permanecido irresuelto desde la separación de La Gran Colombia en i831, y en el que hasta los Reyes de España y un grupo de expertos suizos habían intervenido a petición de los países litigantes (Neale-Silva 229). Que Rivera estaba ampliamente familiarizado con los detalles del conflicto son testigo sus notas consignadas en los "Apuntes del Cuaderno del Vaupés". Allí el autor traza la historia de las negociaciones entre ambos países remontándose a los acuerdos firmados en I833 y i844 como "evidencia ... de los derechos de Colombia" ("Apuntes" 39). Con base en estos precedentes, Rivera además hace una serie de observaciones destinadas a mostrar las inconsistencias del mapa de la Oficina de Longitudes que servía de referencia a las autoridades colombianas: "El Guéjar está mal levantado. El Cuinamía no desemboca en aquel sitio sino en el Ariari ... El Cafre, llamado erróneamente Cabra en el mapa, no desemboca antes del Salto Angostura sino debajo de éste" (40). La función de Rivera en la Comisión apuntaba entonces a restaurar los límites nacionales a una posición original perdida, olvidada incluso por la cartografía oficial, pero cuya legitimidad descansaba en la historia y en la observación empírica del agrimensor. Se trataba así de recuperar, de volver a hacer visibles las orientaciones espaciales establecidas desde el surgimiento de la República en la frontera amazónica.

Desde el inicio, la Comisión estuvo plagada de malentendidos y reveses. Rivera no logró entenderse con Justino Garavito, jefe de la delegación colombiana, y la contraparte venezolana, encargada de la logística del viaje y el suministro de equipos, incumplió con lo acordado retrasando considerablemente los trabajos de demarcación. De hecho, fueron tantas las tensiones que el autor abandonó temporalmente su cargo para emprender un viaje a cuenta propia por la región con el fin de hacer observaciones sobre el terreno y averiguar sobre las penetraciones ilegales de los empresarios del caucho. Fue un recorrido de varias semanas por los ríos Inírida y Guaviare, hecho en canoa con bogas indígenas contratados, en una zona de triple frontera entre Colombia, Venezuela y Brasil que le 
daría una idea clara de la alarmante ausencia del Estado, el descuido de los límites territoriales y los abusos de la industria cauchera contra trabajadores sometidos mediante el sistema de endeudamiento o "enganche". Al culminar el viaje, Rivera reestableció relaciones con las autoridades colombianas - aunque las rencillas no se borrarían justificando su temporal abandono de cargo como producto de un genuino deber patriótico (Rivera, "Informe" 54). Una vez ubicado en Manaos, siguiendo la ruta de regreso a Bogotá, el escritor se entera además de las recientes concesiones de tierras hechas por el gobierno peruano en la región del Putumayo sobre la que Colombia reclamaba derechos. ${ }^{7}$ Estos factores lo llevan finalmente a redactar un Informe secreto junto con su compañero, el ingeniero y astrónomo Melitón Escobar.

Dirigido al Ministro de Relaciones Exteriores, el Informe era en cierta forma una justificatoria de Rivera por sus acciones, un documento de denuncia sobre la pérdida de soberanía nacional y, en especial, un acto performativo del agrimensor. Rivera relata su encuentro con colonos y con diversos pueblos indígenas de la zona a quienes instruye en cuestiones de nacionalidad y fronteras:

Nosotros aprovechamos las ocasiones que se presentaron para transmitirles algunas nociones sobre su nacionalidad y darles explicaciones gráficas acerca de los límites de Colombia en aquellos dominios. Muy complacidos recibían la noticia de que eran colombianos, lo que sabían por primera vez ... El comisionado [Rivera] ... les advirtió que sólo debían obedecer las leyes y autoridades colombianas y elevar sus reclamos al Comisario Especial de San Rafael del Meta ... Las mismas instrucciones les comunicó a los señores José de la Espriella y doce compañeros más, todos de nacionalidad colombiana, que son colonos en el Alto Inírida. (44-45)

Como sostiene Jennifer French, la narrativa del Informe "may be read as a kind of utopian revision of first contact: the white men arrive not to displace the Indians from their land, but to establish a bond of national solidarity" (130). Pero esto solamente es posible en la medida en que la coincidencia entre límites y ley es restituida, visualizada y reconocida. En un sentido estricto, los indígenas no son objeto de un contacto inicial sino, para ser exactos, instruidos en el reconocimiento de una distribución geográfico-espacial nacional preexistente en la que ya estaban inscritos. El acto de Rivera, el agrimensor, corresponde aquí tanto a la re-producción de ley a través de la relación de límites como a la re-producción del pueblo (quienes ya eran "colombianos" sin saberlo) en tanto sujeto creado por la ley. 
No obstante, el trabajo del agrimensor se complica tan pronto se confronta con la volatilidad generada por la economía del caucho. Esta se le presentaba a Rivera como la fuga de la soberanía nacional a través de la movilidad difusa de la mercancía:

La mayor parte del caucho que sale por el Orinoco y el Río Negro es cosechado en los bosques colombianos ... No obstante, en las dos únicas salidas para el exterior ... no se registra un solo bulto de caucho como de procedencia colombiana ... según datos que nos han suministrado los colonos mismos, hay más de ochocientos caucheros, brasileños y venezolanos, que jamás han pagado a Colombia un solo centavo por derechos de extracción. (48-49)

Si por un lado el desorden limítrofe impedía un efectivo control arancelario sobre la extracción y la comercialización del caucho, por otro lado creaba las condiciones para la suplantación del Estado a través de agentes ilegítimos que pretendían actuar en su nombre. Rivera, por ejemplo, describe en gran detalle el caso de Leonidas Norzagaray Elicechea, un colono que "se decía dueño absoluto de los territorios caucheros de la región", quien "había marcado bastas zonas como de su propiedad", y además se había proclamado "representante de la autoridad y la Ley" colombianas en la zona (52-53; énfasis mío). Se trataba pues de un incidente en el que las demarcaciones eran redefinidas arbitrariamente, dando como resultado la producción de una ley espuria - una pretendida falsificación e impostura del Estado impulsada por la misma industria transnacional del caucho. La situación en general requería de una intervención correctiva, y de hecho Rivera consignó varias recomendaciones destinadas a regular la concesión de terrenos y la explotación de recursos naturales, al tiempo que denunciaba enérgicamente el sistema laboral vigente en las caucherías, el cual describe como "un comercio de esclavitud, disfrazado pero real" (47). Los trabajadores eran enganchados con jugosos adelantos que en la práctica significaban una deuda vitalicia, en ocasiones hereditaria, que los mantenía a merced de sus patrones.

Pese a todo, el Informe pasó desapercibido y - al igual que muchas de las denuncias publicadas por Rivera en la prensa capitalina tras su regreso - sería desacreditado en parte debido a la animosidad que el autor se había granjeado entre los burócratas del gobierno colombiano. ${ }^{8} \mathrm{La}$ respuesta de Rivera a estas circunstancias sería La vorágine. En otras palabras, a un cierto nivel la novela habría estado destinada a restaurar la función del Informe, a rescatar la labor fallida del agrimensor. De ello es indicio la estrategia publicitaria que antecedió a su publicación, con 
anuncios sensacionalistas que en buena medida condicionaron la primera recepción crítica de la novela como texto de carácter histórico y documental. ${ }^{9}$ A lo cual contribuyó también Rivera con sus propias declaraciones, en las que defendía la "trascendencia sociológica" y "patriótica" del libro, cuyo objetivo no había sido otro que el de "buscar la redención de esos infelices que tienen la selva por cárcel" ("Respuesta a Luis Trigueros" 97). Sin embargo, en tanto poética ficcional, La vorágine desplazará la norma que le asignaba su vínculo generativo con el Informe, y es precisamente en esos desplazamientos donde se abre la grieta que separa a Rivera el agrimensor de Rivera el escritor.

TERRITORIOS DE EXCEPCIÓN

La vorágine incorpora en su tejido narrativo dos nefastos acontecimientos históricos marcados por violaciones a los derechos humanos y disputas territoriales que revelaron al mundo los horrores de la explotación del caucho en la Amazonía. El primero es el famoso "Escándalo del Putumayo" (I907-I9I4) asociado con las incursiones de la Peruvian Amazon Company (PAC) - un consorcio anglo-peruano presidido por el empresario cauchero Julio César Arana - en el territorio del mismo nombre sobre el cual Colombia y Perú reclamaban jurisdicción. En I905 ambos países firmaron un Tratado de Arbitraje que había dejado al Putumayo en un limbo jurídico, lo cual facilitó la colonización privada por parte de la PAC, aunque se sabía también que la empresa contaba con el beneplácito secreto del gobierno peruano (Gray 34). Debido a los abusos contra la población indígena, la PAC pronto se convirtió en sinónimo de genocidio y esclavitud, desencadenando a su vez un escándalo político y humanitario de proporciones internacionales que involucró a gobiernos y sociedades antiesclavistas en ambos lados del Atlántico. El segundo episodio, menos sonado pero igualmente cruento, es conocido como "La Funera" (I9I2I92I), luego del régimen de terror ejercido por el exmilitar venezolano Tomás Funes en el Alto Río Negro - justamente el área visitada por la Comisión en la que participó Rivera. Funes lideró una sanguinaria revuelta de caucheros contra las autoridades locales en San Fernando de Atabapo, llegando a monopolizar el comercio del caucho y a administrar justicia en esa región por casi diez años (Iribertegui 2IO-2I2). La PAC y La Funera se constituyeron así en siniestras fuerzas para-legales que vinculaban la administración poblacional y la extracción de recursos con la expansión del capitalismo transnacional en territorios de excepción y virtualmente suspendidos en un vacío legal.

La inclusión de estos acontecimientos en la novela consolidará el motivo final del viaje que estructura la narración. La vorágine se inicia con 
la fuga de Arturo Cova y Alicia, quienes huyen de Bogotá perseguidos por la justicia a causa de sus amoríos clandestinos y los pleitos judiciales que pesan sobre Cova. La pareja se dirige a los Llanos Orientales donde conoce a otra pareja, Griselda y Franco, y se entera de los negocios de Barrera, un oscuro enganchador encargado de reclutar trabajadores para las caucherías del Vichada. El viaje se convierte en una excursión de retaliación personal cuando Alicia y Griselda huyen con Barrera, dejando a sus compañeros sedientos de venganza por la "ofensa increíble" (Rivera, La vorágine 75 ). Y, finalmente, ya en el contexto amazónico, el viaje se transformará en un programa de denuncia social y redención del territorio nacional luego de que Cova y su grupo se enteren de los crímenes del Putumayo y La Funera a través de los testimonios de narradores secundarios como Clemente Silva y Ramiro Estébanez.

En efecto, tras escuchar las desventuras de Clemente Silva en las caucherías de la PAC, Cova formulará, con su característica afectación emocional, el programa político de los expedicionarios: "sus tribulaciones nos han ganado para su causa. Su redención encabeza el programa de nuestra vida. Siento en mí ... el ansia de contender con esta fauna de hombres de presa, a quienes venceré con armas iguales" (I38-I39). Más tarde especula que sus acciones llamarán la atención del cónsul colombiano, quien llegaría con "una guarnición de gendarmes, a devolvernos la libertad" y a reestablecer la presencia del Estado en la zona (I4I). Como sostiene Monserrat Ordóñez, el programa político en La vorágine, al menos desde la perspectiva de los narradores principales, "no es de reforma social ni de revolución" (493), sino que se limita a hacer un "llamado a las autoridades centrales a defender a sus ciudadanos y el territorio nacional" contra las penetraciones de agentes foráneos y "al margen de los indígenas" (495). En un sentido, el programa anunciado por Cova se hace eco del programa del agrimensor en el Informe: su propósito no es otro que la reconstitución de la relación entre límites y ley como fundamento de la soberanía estatal. De ahí también la búsqueda incansable de funcionarios gubernamentales - cónsules, ministros, comisarios - por parte de los principales personajes de la novela. Pero a diferencia de lo que ocurría en el Informe, los indígenas estarán excluidos del espacio simbólico y territorial de la nación en La vorágine, ya que "the novel bars access to the indigenous people who bore the brunt of violence in the rubber trade", y la narración "is entrusted to white characters" (Beckman 185). Cova, por ejemplo, describe a los guahibos con quienes el grupo pasa unas semanas como "tribus rudimentarias y nómades [que] no tienen dioses, ni héroes, ni patria, ni pretérito, ni futuro" (Rivera, La vorágine 86). Por otra parte, resulta paradójico que Cova termine invocando al Estado 
como agente de restitución, cuando en principio habían sido las mismas estructuras legales del Estado las que lo habían expulsado de la capital y lo habían convertido en prófugo. Pero lo que el narrador y muchos de los personajes excluyen o no quieren ver, aparecerá en cambio inscrito en la novela a través de episodios marginales que cuestionan las promesas del programa político de Cova, insinuando además la complicidad existente entre el Estado modernizador liberal latinoamericano y el expansionismo colonizador de las compañías del caucho.

Me referiré a un episodio en particular, insertado en la narración de Clemente Silva, en el que éste recuerda una conversación sostenida con Balbino Jácome durante los días en que un funcionario del gobierno peruano visita las instalaciones de la PAC para investigar las acusaciones contra la empresa. Jácome es un personaje misterioso que practica el juego de la doble traición. Por un lado, se ha ganado la confianza de los vigilantes de la PAC y les sirve de espía. Por otro, sin embargo, tergiversa los datos que transmite para evitar la aplicación de castigos brutales, ayuda a escapar a peones y distribuye información clandestina con el propósito de crear conciencia sobre la situación en las caucherías. En la novela es Jácome quien despacha en secreto los recortes del diario iquiteño La felpa - el primer diario peruano en revelar los crímenes de Arana y la PAC - con la esperanza de que "al quedar por ahí volteando, [dieran] con un lector que los aprovechara" (127). ${ }^{\text {IO }}$ Esta escritura itinerante, que marcha camuflada por la vasta geografía selvática, agudiza el descontento de los trabajadores y articula entre ellos una conciencia de rebelión. Los vigilantes de hecho consideraban la posesión de esas hojas como un acto de insubordinación, al punto que cuando descubren a un grupo de peones escuchando a otro leerlas en voz alta les infligen severos castigos: "Al lector le cosieron los párpados con fibras de cumare y a los demás les echaron en los oídos cera caliente" (I24).

Curiosamente, Jácome redirige las acusaciones de La felpa al encuentro del lector anónimo, del gomero desconocido de los seringales, contrastando con la interpelación constante a los funcionarios estatales que parece ser la norma en la novela. Esto es significativo por cuanto el movimiento indiscriminado de esas páginas, sustraídas aquí a la interpretación del interlocutor oficial, establece algo similar a lo que Jacques Rancière denomina como "a community of readers as a community without legitimacy", esto es, "a community formed by the random circulation of the written word" (I4). Es además un hecho sintomático que Jácome prefiera potenciar la formación de esa comunidad ilegítima de lectores, una comunidad amorfa e indefinida, en vez de denunciar los crímenes ante las autoridades teniendo la oportunidad de 
hacerlo. Cuando Silva intenta persuadirlo de que aprovechen la llegada del funcionario para revelar los sufrimientos e injusticias causados por los empresarios del caucho, Jácome responde con una desconcertante teoría:

Líbrenos Dios de que se compruebe crimen alguno, porque los patrones lograrían realizar su mayor deseo: la creación de Alcaldías y de Panópticos, o mejor, la iniquidad dirigida por ellos mismos. Recuerde que aspiran a militarizar a los trabajadores, a tiempo que en Colombia pasan cosillas reveladoras de algo muy grave, de subterránea complicidad ... Óigame este consejo: ¡no diga nada! Dicen que el que habla yerra, pero el que hable de estos secretos errará más. Vaya, predíquelos en Lima o en Bogotá, si quiere que lo tengan por mendaz y calumniador. (I30; énfasis mío)

Estas palabras podrían interpretarse como el triunfo final de los opresores y la aceptación cínica de la impunidad, o simplemente como producto de la lealtad nacional del personaje en contra de los peruanos. Pero creo que el comentario exige una lectura desde otra perspectiva. Jácome es el único personaje que rechaza la oportunidad de testificar ante un funcionario estatal, y en ese gesto La vorágine intenta hacer visible la subterránea complicidad, y la potencial identidad operativa ("alcaldías", "panópticos", "militarización") entre el Estado liberal latinoamericano (en sus variadas encarnaciones nacionales) y el brutal modelo de colonización extractiva de las compañías del caucho. Las mismas referencias a Lima y Bogotá, a los centros urbanos de poder, ponen de manifiesto que lo que sucedía en los territorios de excepción amazónicos no era del todo ajeno a los mecanismos de administración y control disciplinario inherentes a los proyectos republicanos de modernización liberal. En efecto, hay razones históricas que apuntan en esta dirección. De acuerdo con Ana Pizarro, los barones del caucho podían ser vistos como agentes de modernidad, civilización y progreso nacional en lugares "donde las fronteras [estaban] siendo demarcadas y en un momento de tensiones políticas con los países limítrofes" (I2O). Por ejemplo en el Perú, pese a la vigencia del tratado de no intervención, el presidente Augusto B. Leguía apoyaba las incursiones ilegales de la PAC en el Putumayo con miras a una posible anexión del territorio sustentada en la noción de uti possidetis juris. Como afirma Andrew Gray, la PAC "podría aparecer como una compañía privada independiente, con respaldo británico fuera del país, mientras que, dentro del Perú, [Julio César Arana] era el hombre patriótico de la frontera que protegía la integridad de los límites nacionales" (35). Algo similar sucedía con Tomás Funes en el Alto Río Negro, quien oficiaba de representante informal del régimen de Juan Vicente Gómez en la frontera amazónica 
venezolana. Y recordemos, por otra parte, el episodio del colono cauchero Norzagaray Elicechea, el pretendido agente del gobierno colombiano en la región referido por Rivera en el Informe. Que el documento hubiese sido finalmente desacreditado en Bogotá deja ver hasta qué punto los poderes centrales colombianos habían terminado implicándose, por negligencia o confabulación, en las iniciativas y la economía de exportación de los barones del caucho.

En la novela la intervención de Jácome expone esta complicidad, sembrando la duda sobre las bondades del programa político de Cova, e incluso sobre el proyecto nacional restaurativo de Rivera el agrimensor. Esto en razón de que, para decirlo con Rafael Gutiérrez Girardot, la "suspensión de la ley" o el "homo homini lupus del liberalismo clásico" que los personajes de La vorágine presencian al entrar en las caucherías, era también "el sustrato sobre el que se sostenía la sociedad colombiana desde el siglo XIX y que se puso de manifiesto en la Guerra de los Mil Días" (234). El "no diga nada" de Jácome lleva entonces la exigencia imperativa de una interrupción crítica, o en otras palabras, la potencial suspensión de la excepcionalidad soberana que imperaba en los territorios amazónicos y en las repúblicas latinoamericanas que pretendían demarcarlos, administrarlos y usufructuarlos. Lo que este episodio parece sugerir es que en el contexto de la explotación transnacional del caucho la denuncia corría el peligro de perpetuar la barbarie de lo denunciado - justamente porque la presunta instancia de restitución, el Estado, estaba implicada en el crimen. ${ }^{\text {II }}$

LA CÁRCEL VERDE: DEUDA Y REBELIÓN

Con todo, el vínculo entre el Estado liberal latinoamericano y el modelo de explotación extractiva imperante en las caucherías no era simplemente coyuntural sino que verificaba una transformación esencial de la razón de Estado en lo que Michel Foucault denominara como "razón gubernamental moderna". En sus lecciones del Collège de France dedicadas al nacimiento de la biopolítica, Foucault sostiene que a finales del siglo XVIII ocurre un giro importante en el cual la razón de Estado se "autolimita" en sus funciones, siguiendo el paradigma de "gobernar menos" (26) y los preceptos de la economía política como ciencia encargada de develar los "límites naturales" del arte de gobernar (30). Se trata, en otras palabras, del despliegue del modelo político y económico liberal, con su manufactura de libertades y su posicionamiento del mercado como "lugar de veridicción" del buen gobierno (50). ${ }^{\mathrm{I2}} \mathrm{Si}$ bien esto implicaba una subordinación de la política a la economía (el clásico laissez-faire liberal), Foucault observa que este "arte de gobernar lo menos posible [corresponde] a un refinamiento 
interno de la razón de Estado; es un principio para su mantenimiento, para su desarrollo más exhaustivo, para su perfeccionamiento" (44). Es decir que cuanto más frugal e invisible se hace el Estado más efectivo y potente será su radio de acción e influencia.

En el contexto de la bonanza del caucho en la Amazonía, la autolimitación de la razón estatal, es decir, el "dejar hacer" liberal por medio del cual el capitalismo extractivista expandía las fronteras nacionales, correspondía a un continuo proceso de redefinición y trazado de los límites espaciales perpetrado por un sinnúmero de agentes (enganchadores, contratistas, colonos, incluso científicos) al servicio de las compañías. Es conocido el caso del francés Eugenio Robuchon, un miembro de la Sociedad Geográfica de París a quien los dirigentes de la PAC, bajo recomendación del gobierno peruano, habían contratado para que hiciera una exploración general de los territorios ocupados por la compañía. Robuchon desapareció en circunstancias sospechosas en 1907, poco tiempo después de iniciar sus labores. Sus manuscritos, sin embargo, fueron rápidamente editados y publicados por los administradores de la PAC, llevando un prólogo de Carlos Rey de Castro, cónsul peruano en Manaos, quien aseguraba que aquellos tenían "fuerza probatoria en cualquiera circunstancia en que sea preciso atestiguar cómo las energías peruanas se han ejercitado en las zonas que nos disputan algunos países vecinos" (VIII). ${ }^{13}$ En efecto, muchos funcionarios medios de la compañía podían terminar convertidos en agentes informales de agrimensura, es decir, en ejecutores efectivos de la constante expansión de límites sancionada por un paradigma de gobernabilidad autolimitada - que estaba en la base de los procesos de acumulación originaria en la Amazonía de cambio de siglo. ${ }^{14}$ Sus actos de delimitación correspondían así a actos creadores de ley. En la práctica esto provocaría el despojo sistemático de tierras a las comunidades para "abrirlas" a la extracción masiva de caucho y, simultáneamente, la conversión de la población desposeída en mano de obra sometida a los imperativos del capital por el mecanismo del enganche y la figura de la deuda. La producción de sujetos endeudados era el resultado inmediato de las nuevas orientaciones espaciales y la "fijación móvil" de las fronteras agenciadas por las compañías y sus funcionarios.

Como es bien sabido, el sistema de explotación de las caucherías descansaba en el crédito y la deuda como dispositivos de movilización de recursos y administración poblacional. Tanto así, que a lo largo de todo el proceso de comercialización del caucho el dinero en efectivo aparecía únicamente al nivel de las transacciones de las casas exportadoras. A los intermediarios se les abonaba el pago con bienes y créditos, "los cuales pasaban, a través de una deuda descendiente, a los trabajadores, a cambio 
de caucho" (Gray I7). El "contrato" del peón - muchas veces forzado a aceptarlo bajo amenazas de muerte - incluía un anticipo que debía ser reembolsado en trabajo. ${ }^{15}$ Como señala David Graeber, para que la explotación del caucho tuviera la fachada de una empresa legítima debía sostenerse en principios morales, "and the only morality the company knew was debt" (350). El anticipo generalmente era utilizado para cubrir gastos de trasporte, ropa o herramientas, y en la práctica resultaba imposible de saldar, pues lo poco que ganaba el trabajador solo le servía para abastecerse de comida y artículos de sobrevivencia cuya distribución era monopolizada por los almacenes de las compañías a precios exorbitantes. La deuda permanecía intacta y la más de las veces se acrecentaba, quedando el peón sometido a sus acreedores por años, incluso de por vida, en lo que era una forma de esclavitud efectivamente sancionada por un mecanismo crediticio armonizado con el sistema liberal de libertades. En La vorágine el tema de la deuda, enunciado por los narradores secundarios, manifiesta recurrentemente este limbo improductivo y en última instancia letal en el que permanecían atrapados los peones. "Bien saben los gomeros", dirá Ramiro Estébanez, "que el oro vegetal no enriquece a nadie. Los potentados de la floresta no tienen más que créditos en los libros, contra peones que nunca pagan, sino es con la vida" (Rivera, La vorágine I8I).

Por otra parte, hay que considerar que la deuda, como ya Friedrich Nietzsche lo había notado, es también el principio genealógico de la culpa y de la mala conciencia. ${ }^{16} \mathrm{Y}$ es por esta razón que el trabajador de las caucherías, en tanto deudor, era producido como subjetividad culposa desde el momento mismo del enganche: un sujeto culpable de su sometimiento a los acreedores y responsable de su esclavización. En la medida en que la deuda se mantenía, la culpa se hacía inexpiable para el peón, como también lo sujetaba al imperativo imposible de expiarla, lo cual lo llevaba literalmente a "pagar con su vida" en el trabajo monótono y circular de la recolección de caucho para saldar el débito. La subjetividad culposa que fabrica la deuda solo puede expresar existencias espectrales, suspendidas entre la vida y muerte, y expuestas a la voluntad implacable de los acreedores. Y es precisamente desde esta perspectiva que podemos releer una de las metáforas centrales del texto de Rivera: la cárcel verde. Esta representa, por así decirlo, la concreción espacial específica de la relación entre deuda y culpa en La vorágine. Son famosas las primeras líneas del monólogo con el que se inicia la segunda parte de la novela: “ $\mathrm{iOh}$ selva, esposa del silencio, madre de la soledad y de la neblina! ¿Qué hado maligno me dejó prisionero en tu cárcel verde?" (La vorágine 77 ). La selva envuelve entonces una experiencia de confinamiento y reclusión, es decir, 
de demarcaciones y límites estrictos que no solo disciplinan la movilidad, sino que también actualizan constantemente la indistinción entre vida y muerte. De ahí que la cárcel verde, el espacio selvático territorializado por la economía extractivista, sea al mismo tiempo referida como "catedral de pesadumbres" (77) y "cementerio enorme" (78), imágenes que parecieran aludir a la generación de comunidades espectrales atrapadas dentro de la dinámica expansiva e indeterminada del crédito. En otros pasajes de la novela, sin embargo, la selva evoca una enormidad inabarcable, un "laberinto" (77) sin principio ni fin, una vastedad de "espacios infinitos" (149). Pese a la aparente desemejanza, ambas descripciones captan, en diferentes niveles, la situación misma del sujeto cauchero. La deuda y la culpa hacen de la selva una cárcel verde, pero en la medida en que ambas son potencialmente infinitas - esto es, incalculables e inexpiables para el trabajador - el espacio selvático representa, al mismo tiempo, una totalidad indefinida y desbordada dominada por un poder económico difuso que se pliega sobre la vida humana y no humana para instrumentalizarlas hasta el agotamiento. ${ }^{17}$

Es en este punto que podemos retomar la discusión avanzada en la sección anterior sobre el desfase entre el programa político de Cova y la intervención crítica de Balbino Jácome en la novela. Si la autolimitación de la razón estatal constituye el trasfondo que verifica la complicidad entre el Estado liberal latinoamericano y las compañías caucheras -produciendo un modelo de gobernabilidad fundado en la expansión de fronteras, la expropiación de tierras y la deuda - el "no diga nada" de Jácome no solo apuntaría a exponer dicha complicidad sino que abriría una dimensión insospechada en La vorágine: la inscripción literaria de aquellos que rechazaban por igual las interpelaciones estatales y las máquinas de guerra de la colonización cauchera en tanto manifestaciones de un mismo poder soberano. Es significativo, por ejemplo, que cuando Cova intenta organizar una rebelión de peones en las Barracas del Guaracú, mientras espera la improbable llegada del cónsul colombiano, los trabajadores se nieguen a colaborar y se muestren recelosos, a pesar de que lo han visto humillar a uno de los capataces de la estación. Franco, su compañero de viaje, se lo expresa con alarma: "he procurado cumplir tus órdenes respecto a la insurrección; pero nadie quiere meterse en sublevaciones, desconfían de nuestros planes y de ti mismo" (I72). Esta desconfianza es signo de la brecha que separa el programa de Cova - operante dentro de una lógica estatal - de los intereses de los peones, quienes intuyen que la planeada insurrección no corresponde a una verdadera ruptura con el estado de cosas. 
Me parece que esta brecha representa un espacio latente desde el cual podemos examinar otro tipo de prácticas y estrategias insurreccionales que se sustraían a las formas del poder constituido durante la bonanza cauchera en la Amazonía. De hecho, La vorágine registra de manera muy tenue una de las modalidades más sobresalientes de rebelión en los campos de extracción del caucho: las deserciones de peones que se negaban a someterse al terror y la explotación imperantes, organizándose en comunidades autónomas a lo largo del vasto territorio selvático. Eran agrupaciones cimarronas conformadas por mestizos e indígenas de distintas etnias (huitotos, carijonas, guahibos, yacunas, andoques, mirañas, boras, muinane, tanimucos, entre otros). Según el antropólogo Roberto Pineda, estos enclaves multiétnicos constituían, junto con los alzamientos armados y las modalidades de no colaboración en el lugar de trabajo, las principales formas de resistencia colectiva en el contexto de la colonización cauchera (139). Hubo dos casos de cimarronismo que llegaron a tener gran resonancia en su momento: el del Refugio de Campoamor y el del Campamento de Atenas. Este último eventualmente sufriría los rigores de las incursiones tanto de empresarios caucheros como de escuadras militares, lo cual generó un importante movimiento rebelde liderado por el jefe huitoto Yarocamena, cuya memoria se ha mantenido hasta hoy en las tradiciones orales de varias etnias del noroeste amazónico (155) ${ }^{18}$ Pineda sostiene que en eventos como estos "se puso a prueba, en cierta forma, el poder del indígena respecto al del cauchero y, en forma más global, frente a la sociedad blanca" ( 167 ). En la novela, los indios maipureros con los que viajan Cova y su grupo se refieren a estas comunidades como "tribus cosmopolitas" y como colectivos de resistencia conformados por "prófugos de siringales desconocidos, hasta del Puyumayo y del Ajajú, del Apaporis y del Macava [que] tenían correderos entre la selva para cuando fueran patrullas armadas a perseguirlos" (Rivera, La vorágine IOI). A los expedicionarios incluso se les aconseja evitar a toda costa el encuentro con estas colectividades, "porque si dábamos con los prófugos nos tratarían como a enemigos" (IOI).

La referencia al cimarronismo amazónico es fugaz, justamente porque la novela carece de un lenguaje para abordar aquellos acontecimientos que exceden su norma y se escapan a la axiología nacional-estatal desde la cual los principales personajes articulan la narración. No obstante, resulta sintomático que, a pesar de todo, el texto de Rivera se deje transitar por esos acontecimientos. Se trata en realidad de paisajes políticos potenciales, los cuales, pese a su marginalidad y virtual invisibilidad, sobreviven en $L a$ vorágine como la huella de otra historia - la historia de quienes se rebelaban para borrar y desdibujar los trazos de agrimensura, los actos de 
límites y ley en tanto actos de expropiación que generaban formas de vida suspendidas en la deuda, la culpa y el trabajo explotado. Hacia el final de la novela, cuando Arturo Cova, antes de perderse en la selva, le deja a Clemente Silva el manuscrito de sus aventuras, es decir, el texto mismo de La vorágine, el personaje comenta con cierta impostura que el documentonovela contiene "la historia nuestra, la desolada historia de los caucheros" (20I). Y sin embargo, Cova se corrige inmediatamente para añadir: “¡cuánta página en blanco, cuánta cosa que no se dijo!” (20I). La ironía de este comentario es que en esas páginas en blanco, indeterminadas y por lo tanto abiertas a otras inscripciones históricas, quizás se encuentre lo que separa a Rivera el agrimensor de Rivera el escritor, al agente de la soberanía estatal del creador cuyo texto "borra límites y contamina espacios" (Molloy 492). Esas páginas en blanco sugieren la presencia elusiva de aquello invisible e inaudible - las prácticas cimarronas que intentaban desbordar las fronteras espaciales y la subjetividad culposa de la cárcel verde - pero siempre ya existente no solo en La vorágine, sino en la convulsionada modernidad amazónica de la que hace parte indiscutible la novela de Rivera.

University of Utah

NOTAS

I Sobre el impacto que la práctica de la agrimensura tuvo en el desarrollo del pensamiento de Thoreau, véase el reciente estudio de Patrick Chura, Thoreau. The Land Surveyor.

2 Ver Las fuerzas extrañas (1906) de Lugones; El tungsteno (I93I) de Vallejo; y La serpiente de oro (1935) de Alegría, textos en los cuales este tipo de personajes tiene gran relevancia. Otros ejemplos de autores vinculados a la agrimensura, esta vez en el contexto paraguayo, son el escritor anarquista Rafael Barrett y el poeta vanguardista Hérib Campos Cervera.

3 Como recuerda Eduardo Neale-Silva, biógrafo del escritor, la tesis fue ampliamente comentada en la prensa bogotana de la época (132). De hecho el documento fue publicado en 1917 , pocos meses después de que Rivera hiciera su defensa.

4 Por ejemplo, para David Viñas, Arturo Cova representa al intelectual populista antioligárquico latinoamericano que emprende un viaje curativo de la ciudad al campo, pero cuyo proyecto se derrumba en el contacto con la alteridad de la selva (5-6); Montserrat Ordóñez sostiene que "el concepto de nacionalidad" colombiana establece los lazos de solidaridad entre los principales personajes de la novela (495); Doris Sommer señala que La vorágine se inscribe dentro de 
la tradición de las novelas fundacionales, aunque lo hace desde el desencanto hacia los programas liberales defendidos en obras anteriores (470); para Carlos Alonso el texto de Rivera constituye un manifiesto poético de reacción contra las vanguardias y una afirmación de las temáticas nacionalistas de la Generación del Centenario (I44-I66); Sylvia Molloy, en otro registro, interpreta la novela como proceso de "desordenamiento y contaminación" (495) que hace inoperantes las ficciones del romanticismo y el modernismo latinoamericanos. Recientemente, Jennifer French ha argumentado que en La vorágine confluyen por igual la perspectiva "liberal", centrada en la cuestión de la nacionalidad, y la perspectiva "radical" que intenta subvertir el neoimperialismo británico en América Latina (I3I).

5 Para una discusión sobre la proscripción y su relación con la excepción soberana, véase también de Giorgio Agamben, Homo Sacer: Sovereign Power and Bare Life (IO4-III).

6 Esto lo señala Hecht respecto a la influyente labor de Euclides da Cunha en la comisión peruano-brasileña de 1905 encargada de trazar los límites entre ambos países en el Alto Purús. Ver The Scramble for the Amazon and the Lost Paradise of Euclides da Cuna (9;347).

7 El Putumayo sería reconocido como territorio colombiano solo hasta I927 con la ratificación del Tratado Salomón-Lozano.

8 Rivera colaboraba con frecuencia para diarios como El Tiempo, El Espectador y El Gráfico. Una selección de algunas de estas contribuciones se encuentra en la compilación de Hilda Soledad Pachón-Farías, José Eustasio Rivera intelectual. Textos y documentos: 1912-1928 (59-74).

9 Uno de estos anuncios decía: “La vorágine. Novela original de José Eustasio Rivera. Trata de la vida de Casanare, de las actividades peruanas en la Chorrera y en el Encanto y de la esclavitud cauchera en las selvas de Colombia, Venezuela y Brasil. Aparecerá el mes entrante" (cit. en Neale-Silva 298).

1o Se trata de la ficcionalización de un hecho real en la novela. Fue en dos periódicos de Iquitos, La felpa y La sanción, donde el periodista peruano Benjamín Sandaña Rocca hizo en 1907 las primeras denuncias que darían inicio al "Escándalo del Putumayo".

II En la novela esta dinámica es ejemplificada en la figura de Cova, el agente que asume la bandera de la denuncia y la reconstitución del Estado. Como fue notado por Ordóñez, si bien las "grietas y contradicciones" del personaje hacen difícil encasillarlo, también es cierto que su actuar constantemente "reproduce el mismo terror que denuncia” (438).

I2 Como comenta Foucault, “¿qué quiere decir autolimitación de la razón gubernamental? ... creo que a grandes rasgos es lo que llamamos 'liberalismo'” (39). Por otra parte, para el autor, el fenómeno epocal de la biopolítica, como 
mecanismo moderno de regulación poblacional, solo puede comprenderse desde el horizonte de "ese régimen que es el liberalismo" (4I).

I3 Véase de Eugenio Robuchon, En el Puyumayo y sus afluentes (1907). La historia del explorador francés, por otra parte, es ficcionalizada en La vorágine en el episodio del mosiú a quien Clemente Silva le sirve de guía.

I4 Como sostiene Karl Marx en Capital, la acumulación originaria o primitiva precede a la acumulación capitalista y representa su punto de partida (873). Se trata, en otras palabras, del momento inicial por el cual se lleva a cabo la separación entre la comunidad y sus medios básicos de subsistencia, como la tierra: "The expropriation of the agricultural producer, of the peasant, from the soil is the basis of the whole [capitalist] process" $(876)$.

I5 Este era de hecho el método más común para reclutar indígenas, quienes eran obligados a aceptar el adelanto de mercancías que establecía la deuda y la pura formalidad del convenio con la compañía (Graeber 350).

I6 Según argumenta Nietzsche en la Genealogía de la moral, "el sentimiento de culpa (Schuld), de la obligación personal ... ha tenido su origen ... en la más antigua y originaria relación personal que existe, en la relación entre compradores y vendedores, acreedores y deudores" (9I).

I7 Aunque es un tema que excede los propósitos de este ensayo, es importante señalar que la representación de la naturaleza no humana en La vorágine no se limita a su condición de mercancía o materia explotable, sino que simultáneamente opera como instancia que cuestiona los modelos de colonización y modernización descritos en la novela. Esta perspectiva ha venido siendo desarrollada desde los estudios ecocríticos y la ecología política. Jorge Marcone, por ejemplo, sugiere que el fracaso de los héroes modernizadores de la novela de la selva, incluida La vorágine, ilustra la función de una naturaleza que resiste la explotación extractivista y plantea la posibilidad de modelos alternativos de modernización (304-305); para Felipe Martínez-Pinzón el texto de Rivera pone en escena lo que el autor llama "la voz de los árboles", un discurso tejido a partir de la fiebre del protagonista y la poética del modernismo hispanoamericano que problematiza la distinción entre naturaleza y cultura, liberando además "aquella parte de la naturaleza que se niega a convertirse en mercancía” (I4O); por su parte, Mark D.

Anderson y Marcela Reales sostienen que La vorágine disuelve la soberanía del sujeto humanista moderno para abrir "an ecological perspective of the Amazonian environment in which humans are emplaced metabolically within their surroundings" (388).

I8 Pineda señala que casos como los del Refugio de Campoamor y el Campamento de Atenas han llegado hasta nuestros días a través de las tradiciones orales de distintas etnias indígenas, cuyos antepasados más próximos habrían participado en tales movimientos de resistencia. El 
movimiento liderado por Yarocamena, acaecido hacia I9I7, representa "un acontecimiento histórico y simbólico fundamental para las generaciones contemporáneas" que "irradia un contenido libertario" (I67-I68).

\section{OBRAS CITADAS}

A gam B en, gio rgi o. Desnudez. Trad. Mercedes Ruvituso y María Teresa D’Meza.

Barcelona: Anagrama, 20II.

—. Homo Sacer. Sovereign Power and Bare Life. Trans. Daniel Heller-Roazen.

Stanford: Stanford UP, 1998.

A LEG Rí A, C IR O. La serpiente de oro. Lima: Ediciones Peisa, I973.

A LONS o, CAR Los. The Spanish American Regional Novel: Modernity and

Autochthony. Cambridge: Cambridge UP, I990.

ANDERSON, MARK D. Y MARCELA REALES. "Extracting Nature: Toward an Ecology of Colombian Narrative”. A History of Colombian Literature. Ed. Raymond L.

Williams. Cambridge: Cambridge UP, 2016. 363-405.

B E C M M n, ER I C A. Capital Fictions. The Literature of Latin America's Export Age.

Minneapolis: U of Minnesota P, 20I3.

B R OWN, WE NDY. Walled States, Waning Sovereignty. New York: Zone Books, 2010. BURNETT, D. GRAHAM. Masters of All They Surveyed. Exploration, Geography, and a

British El Dorado. Chicago: The U of Chicago P, 2000.

CH U RA, PATRIC K. Thoreau. The Land Surveyor. Gainesville: U of Florida P, 2010.

DA C UnhA, EuClides. À margem da história. São Paulo: Editora Martin Claret,

2006.

f o U Cault, michel. Nacimiento de la biopolítica. Trad. Horacio Pons. Buenos Aires:

Fondo de Cultura Económica, 2007.

F RE NCH, J EN N F E R. Nature, Neo-colonialism, and the Spanish American Regional

Writers. Hanover: Dartmouth College P, 2005.

GAlleg os, Ró Mul o. Doña Bárbara. Caracas: Biblioteca Ayacucho, 1977.

GRAEBer, DA Vid. Debt. The First 5ooo Years. Brooklyn: Melville House, 2012.

GRAY, ANDREW. "Las atrocidades del Putumayo reexaminadas". La defensa de los

caucheros. Grupo Internacional de Trabajo sobre Asuntos Indígenas. Iquitos:

Ceta, 2005. 15-50.

gutiérRez girardot, rafael. “Locus terribilis". La vorágine: Textos Críticos. Ed.

Monserrat Ordóñez. Bogotá: Alianza Editorial Colombiana, 1987. 233-236.

HECH T, s U SAN A в. The Scramble for the Amazon and the Lost Paradise of Euclides

da Cunha. Chicago: The U of Chicago $\mathrm{P}, 2 \mathrm{OI} 3$.

iribertegui, Ramón. Amazonas: el hombrey el caucho. Caracas: Editorial Texto, I987.

KAFKA, FRANZ. El castillo. Madrid: Biblioteca Edaft, 1996.

LUGONES, LE O PO LD O. Las fuerzas extrañas. Madrid: Cátedra, I997. 
MARCONE, JORGE. "De retorno a lo natural: La serpiente de oro, la 'novela de la selva' y la crítica ecológica”. Hispania 81. 2 (1998): 299-308.

MARTÍNEZ-P INZÓN, FELIPE. Una cultura de invernadero: trópico y civilización en Colombia (I808-1928). Madrid/Frankfurt: Iberoamericana/Verveurt, 2016.

MARX, KARL. Capital. Volume I. Trans. Ben Fowkes. London: Penguin Classics, I990. M OLLOY, SYLVIA. “Contagio narrativo y gesticulación retórica en La vorágine." La vorágine: Textos Críticos. Ed. Monserrat Ordóñez. Bogotá: Alianza Editorial Colombiana, I987. 489-513.

n EA Le-Silva, ed uAR D o. Horizonte Humano. Vida de José Eustasio Rivera. Madison: Wisconsin UP, 1960.

NietzSChe, FR IE DR IC H. La genealogía de la moral. Trad. Andrés Sánchez Pascual. Madrid: Alianza Editorial, 1997.

OR D ÓÑ EZ, M ONSERRAT. "La vorágine: la voz rota de Arturo Cova”. Manual de literaturacolombiana. Bogotá: Procultura, 1988. 432-517.

P I N E A, Ro B E R T o. Holocausto en el Amazonas. Una historia social de la Casa Arana. Bogotá:Planeta, 2000.

Pizar ro, anA. Amazonía. El río tiene voces. México: Fondo de Cultura Económica, 2009.

RANCIÈre, JACQUes. The Politics of Aesthetics. Trans. Gabriel Rockhill. London: Continuum, 2007.

RANGel, Al Be RT o. Inferno verde. Cenas e cenários do Amazonas. Manaus: Editora Valer, 2008.

Rey de CAStro, Carlos. "Al lector". En el Putumayo y sus Afluentes. Por Eugenio Robuchon. Lima: Imprenta de la industria, 1907. V-VIII.

Rivera, josé eustasio. "Apuntes del Cuaderno del Vaupés". José Eustasio Rivera Intelectual. Textos y documentos. Ed. Hilda Soledad Pachón-Farías. Bogotá: Universidad Nacional de Colombia, I991. 38-40.

—. "Informe de la Comisión de Límites con Venezuela". José Eustasio Rivera Intelectual. Textos y documentos 1912-I928. Ed. Hilda Soledad Pachón-Farías. Bogotá: Universidad Nacional de Colombia, I99I. 4I-55.

—. Liquidación de las herencias. Bogotá: Editorial La República, I9I7.

-. "Respuesta a Luis Trigueros". José Eustasio Rivera Intelectual. Textos y documentos 1912-I928. Ed. Hilda Soledad Pachón-Farías. Bogotá: Universidad Nacional de Colombia, 1991. 9I-97.

-. La vorágine. Caracas: Biblioteca Ayacucho, 1985.

ROB U CHON, E U G EN IO. En el Putumayo y sus afluentes. Lima: Imprenta de la industria, 1907.

SCH MIT T, CARL. The Nomos of the Earth in the International Law of the Jus Publicum Europaeum. Trans. G. L. Ulmen. New York: Telos Press Publishing, 2006. 
144

SOMMER, D ORIS. "El género deconstruido: cómo releer el canon a partir de $L a$ vorágine". La vorágine: Textos Críticos. Ed. Monserrat Ordóñez. Bogotá: Alianza Editorial Colombiana, $1987.465-487$.

Thoreau, henry david. Walden. Boston: Beacon Press, 2004.

VALLEJ O, CÉSAR. El tungsteno. Barcelona: Plaza \& Janés, 1984.

VIÑ̃S, DA VID. "La vorágine: crisis, populismo, mirada". Hispamérica: Revista de literatura 3. 8 (1974): 3-21. 